\title{
CAMPANHA ELEITORAL NO TWITTER: AS ESTRATÉGIAS DOS CANDIDATOS NA DISPUTA PARA A PREFEITURA DE CURITIBA EM 2016 ${ }^{12}$
}

\author{
Fellipe Herman ${ }^{3}$
}

\section{RESUMO}

Campanhas eleitorais por meio das redes sociais digitais possibilitam a comunicação direta entre o candidato e o eleitor, ampliando a disseminação da informação e a capacidade de mobilizar o eleitorado. Durante períodos eleitorais, grandes quantidades de informações são colocadas à disposição dos eleitores, seja por meio das plataformas dos candidatos, seja por meio de materiais gerados pelos meios de comunicação (como através de debates televisionados). A campanha eleitoral para a disputa do cargo de prefeito da cidade de Curitiba, nas eleições de 2016, teve um total de nove candidatos, os quais participaram de três debates. O objetivo desta pesquisa é verificar de que forma as postagens no Twitter dos candidatos se alteraram durante o período eleitoral. Procurase identificar em que sentido fatores paralelos, tais como debates e pesquisas eleitorais, podem alterar a utilização do Twitter pelos candidatos. Desta forma, duas hipóteses de pesquisa são apresentadas: 1) nos dias em que são realizados os debates, os candidatos utilizam o Twitter com maior intensidade; e 2) debates e divulgações de pesquisas provocam alterações nos temas postados pelos candidatos. Para tal fim, foram analisados 1807 tweets, postados pelos candidatos durante o período oficial de campanha, entre 16 de agosto e 1 de outubro de 2016. As postagens foram analisadas quantitativamente e qualitativamente, através da análise de conteúdo, tendo sido distribuídas em sete temas: Agenda e eventos, Imagem pessoal, Posicionamento, Campanha negativa, Mobilização e engajamento, Promessas e projetos e Outros. Entre os resultados encontrados, verifica-se que os debates provocaram um aumento na quantidade de tweets postados pelos candidatos nos dias correspondentes a tais eventos. Outro achado é que a divulgação de pesquisas eleitorais causou o aumento da quantidade de mensagens referentes ao tema da Campanha negativa postadas pelos candidatos que não lideravam as pesquisas.
\end{abstract}

Palavras-chave: Campanha eleitoral. Comunicação política. Twitter.

\begin{abstract}
Electoral campaigns through digital social networks allow direct communication between the candidate and the voter, increasing the dissemination of information and the capacity to mobilize the electorate. During election periods, large amounts of information are available to voters, either through candidate platforms or through mediagenerated materials (such as televised debates). The electoral campaign for the mayoral race of the city of Curitiba, in the 2016 elections, had a total of nine candidates, who participated in three debates. The objective of this research is to verify how the candidate's Twitter posts change during the election period. It seeks to identify in what sense parallel factors, such as debates and electoral surveys, can change the use of the Twitter tool by the candidates. Thus, two research hypotheses are presented: 1) on the days when the debates are held the candidates use Twitter with greater intensity; and 2) debates and research dissemination bring about changes in the topics posted by the candidates. To that end, we analyzed 1807 tweets, which were posted by the candidates during the official campaign period, between August $16^{\text {th }}$ and October $1^{\text {st }}$, 2016. The postings were analyzed quantitatively and qualitatively through content analysis and were distributed in seven themes: Agenda and events, Personal image, Positioning, Negative campaign, Mobilization and engagement, Promises and projects and Others. Among the results found, the debates provoked an increase in the number of tweets posted by the candidates on the days corresponding to such events. Another finding is that the dissemination of electoral surveys influenced the increase in the number of negative campaign messages posted by candidates who did not lead the polls.
\end{abstract}

Keywords: Electoral campaigns. Political communication. Twitter.

\section{RESUMEN}

A través de las redes sociales, las campañas electorales logran acercar los candidatos a sus electores, valorando una comunicación directa y, también, puntuando la expansión de la información y de la capacidad de movilizar al electorado. Durante periodos electorales, grandes cantidades de información se ponen a disposición de los electores, ya sea a través de las plataformas de los candidatos o por medio de materiales generados por los medios de comunicación (como debates realizados en las cadenas de televisión). La campaña electoral realizada en el año de 2016 para la competencia de la intendencia de la ciudad de Curitiba reunió a nueve candidatos, quienes

\footnotetext{
${ }^{1}$ Submetido em: 25 de Agosto de 2017. Aprovado em: 15 de Setembro de 2017.

2 DOI: http://dx.doi.org/10.5380/recp.v8i3.54819

${ }^{3}$ Graduado em Ciências Econômicas pela Universidade Federal do Paraná (UFPR) e Mestre em Ciência Política pela mesma Universidade. Contato do autor: fellipeherman@gmail.com
} 
participaron de tres debates. El objetivo de esta investigación es verificar de qué manera las publicaciones en Twitter de los candidatos se alternaban a lo largo del periodo electoral. Se busca identificar en qué ámbito las causas paralelas, tales cuales los debates televisados o las encuestas electorales, lograron alternar la utilización de la herramienta Twitter por los candidatos. Desde esta perspectiva, dos hipótesis son presentadas: 1) en los días en los cuales son realizados los debates los candidatos utilizan la red Twitter de manera más intensa; 2) debates y presentaciones de los porcentajes de encuestas provocan cambios en los temas publicados por los candidatos. Para cumplir con estos postulados, se analizaron 1807 tweets, publicados por los candidatos a lo largo del periodo oficial de campaña electoral, desde el 16 de agosto hasta el 1 de octubre de 2016. Los postes fueron divididos bajo temas específicos y analizados de manera cuantitativa y cualitativa. Por su parte, los temas fueron distinguidos a través de siete claves: Agenda y eventos, Imagen personal, Posicionamiento, Campaña negativa, Movilización y participación activa, Promesas y proyectos y Otros. Se verificó entre los resultados encontrados que los debates fueron responsables del aumento en la cantidad de tweets publicados por los candidatos en los días relacionados a dichos eventos. Otra afirmación posible es que la divulgación de las encuestas electorales influenció el aumento de la cantidad de mensajes relacionados con la campaña negativa, textos publicados por los candidatos que no figuraban como primeros colocados en las encuestas.

Palabras clave: Campañas electorales. Comunicación política. Twitter.

\section{INTRODUÇÃO}

Durante os períodos de campanha eleitoral, uma grande quantidade de informação é gerada, seja a partir das próprias campanhas eleitorais dos candidatos, através do Horário Gratuito de Propaganda Eleitoral (HGPE), através das redes sociais digitais e pelos meios de comunicação (por meio de debates televisivos, jornais impressos etc.)

Desta forma, as informações compartilhadas durante estes períodos são dinâmicas e podem alterar os rumos das candidaturas e das estratégias de campanha dos candidatos - uma entrevista na qual as respostas do candidato não sejam convincentes ou em que suas propostas se mostrem impossíveis de serem realizadas, por exemplo, pode gerar munição para os adversários políticos o atacarem.

Portanto, é natural supor que ao longo do período eleitoral as estratégias dos candidatos se alterem e que isso seja refletido em suas campanhas, bem como nas ferramentas de redes sociais digitais, como o Twitter, pois o uso das redes sociais digitais por parte dos agentes políticos está relacionado às estratégias políticas e de ampliação da visibilidade pública (MARQUES; AQUINO; MIOLA, 2014). Devido às possibilidades de ampliação da visibilidade da imagem dos candidatos, o uso das ferramentas de redes sociais durante o período eleitoral é acentuado por todos eles (JUNGHERR, 2016). O Twitter é uma ferramenta que permite a comunicação direta entre candidato e eleitorado e, portanto, permite campanhas mais personalizadas e individualizadas (VERGEER; HERMANS, 2013).

As eleições para a prefeitura da cidade de Curitiba tiveram um total de nove candidatos, dos quais sete fizeram uso do Twitter como estratégia de comunicação política. Durante a campanha, estes candidatos participaram de três debates televisionados, em três momentos diferentes. 
HERMAN, F. Campanha eleitoral no Twitter: as estratégias dos candidatos na disputa para a prefeitura de Curitiba em 2016

Diante do exposto, o objetivo deste trabalho é verificar de que forma as postagens no Twitter dos candidatos à prefeitura de Curitiba se alteraram durante o período eleitoral. Assim, procura-se identificar em que sentido fatores externos, tais como debates e pesquisas eleitorais, podem alterar a utilização de tal ferramenta. A razão para se pesquisar campanhas eleitorais é a de que além da influência que possuem sobre o resultado das eleições, as ferramentas de redes sociais digitais, como o Twitter, permitem a construção de imagens públicas, principalmente através do marketing eleitoral (SCAMMEL, 2015; MARQUES, 2016). Destaca-se, ainda, a ausência de trabalhos que procurem apurar se eventos de campanha podem influenciar as postagens dos candidatos.

O presente artigo será dividido em cinco partes, sendo que na primeira delas será apresentada uma revisão bibliográfica referente ao uso do Twitter durante as campanhas eleitorais. A segunda parte trará um breve cenário das eleições de 2016, como as alterações na lei eleitoral e os candidatos na disputa. A terceira parte apresentará a metodologia de pesquisa e as categorias de análise utilizadas. Na quarta parte será apresentada a análise dos dados, a discussão e, por fim, a conclusão.

\section{COMUNICAÇÃO ELEITORAL NO TWITTER}

Algumas das razões para se dedicar ao estudo das campanhas eleitorais são as de que, além de este período possuir grande influência nos resultados das eleições, ele oferece um grande fluxo de informações, proporciona a possibilidade de contestação e funciona como uma forma de testar a comunicação pública (SCAMMEL, 2015).

Durante as eleições, os candidatos e partidos buscam ampliar a exposição da sua imagem e, para tal fim, várias formas de comunicação são estabelecidas. Desta maneira, os candidatos procuram estar presentes em todos os espaços que possibilitem ampliar sua visibilidade, tais como entrevistas, debates, o Horário Gratuito de Propaganda Eleitoral (HGPE) e a internet (MARQUES, 2016).

Um dos primeiros exemplos desta busca por ampliação da visibilidade diante do eleitorado pode ser representada pela disputa presidencial nos Estados Unidos em 2008, através do "fenômeno Obama". Nestas eleições, o candidato Barack Obama fez uso de todos os tipos de ferramentas tecnológicas para atingir os eleitores, desde mensagens SMS até a publicidade em jogos eletrônicos, passando pelo expressivo uso de redes sociais (GOMES et al., 2009). Portanto, a campanha de Obama mostrou como as oportunidades oferecidas pelas redes sociais digitais podem ser exploradas para campanhas on-line (JACKSON; LILLEKER, 2011). 
Pode-se dizer que foi a partir do efeito Obama que as pesquisas em comunicação e política passaram a se voltar para as redes sociais e sua aplicação não somente em ambientes eleitorais, mas também para a utilização destas ferramentas por atores políticos fora dos períodos eleitorais. Desta maneira, tais pesquisas se tornaram frequentes em quase todos os continentes (JUNGHERR, 2016). Os estudos efetuados abordam não somente eleições para cargos presidenciais, mas também para cargos proporcionais, comparando diversos países no que diz respeito ao engajamento de eleitores e a doações de campanhas (KENSKI; CONWAY, 2016; LASSEN; BROWN, 2011; WILLIAMS; GULATI, 2013; BOR, 2013).

Assim, as ferramentas de redes sociais digitais passaram a desempenhar importante papel durante os períodos de campanha eleitoral, pois possibilitaram aos candidatos uma nova maneira de se comunicar com o eleitorado - ou seja, foi possibilitado que as campanhas se tornassem mais personalizadas e individualizadas (VERGEER; HERMANS, 2013).

As ferramentas de redes sociais digitais, social networks sites (SNS), são definidas por Boyd e Ellison (2007, p. 211, tradução nossa) da seguinte forma:

Definimos sites de redes sociais como serviços baseados na web que permitem aos indivíduos (1) construir um perfil público ou semipúblico dentro de um sistema limitado, (2) articular uma lista de outros usuários com quem compartilham uma conexão e (3) visualizar sua lista de conexões e as feitas por outros dentro do sistema ${ }^{4}$.

Dentre as ferramentas de redes sociais digitais utilizadas durante as campanhas eleitorais, destaca-se o microblog Twitter, que possibilita aos seus usuários encaminhar e receber mensagens, com até 140 caracteres, através da internet, por meio de smartphones e outros aparelhos. Assim, através da ferramenta torna-se possível a comunicação direta e sem filtros entre o candidato e o eleitor, possibilitando-se, além de uma rápida disseminação da informação, a mobilização do eleitorado (PARMELEE; BICHARD, 2012).

Entre as principais funções disponíveis no Twitter, destacam-se: a possibilidade de se publicar mensagens (ou seja, tweets); o compartilhamento de um tweet postado por outro usuário, através da função chamada retweet (RT); a possibilidade de se "favoritar" (favourite) algum tweet emitido; e a menção (@mention) a outros usuários, que pode ser respondida através do @ reply (PARMELEE; BICHARD, 2012).

Diante de tais possibilidades, o Twitter passou a ser incorporado na comunicação política e os candidatos ou agentes políticos passaram a utilizar esta ferramenta para a

\footnotetext{
4 "We define social network sites as web-based services that allow individuals to (1) construct a public or semipublic profile within a bounded system, (2) articulate a list of other users with whom they share a connection, and (3) view and traverse their list of connections and those made by others within the system."
} 
HERMAN, F. Campanha eleitoral no Twitter: as estratégias dos candidatos na disputa para a prefeitura de Curitiba em 2016

divulgação de suas agendas e de suas campanhas eleitorais, bem como para a exposição de sua imagem através de fotos e vídeos (PARMELEE; BICHARD, 2012).

Com a incorporação das redes sociais digitais na comunicação política, elas passaram a desempenhar um papel de destaque dentro das pesquisas acadêmicas sobre campanhas eleitorais, já que podem ampliar os espaços nos quais os candidatos se relacionam com o público — pois, além de permitirem a obtenção de informações a respeito deles, promovem o marketing político, a mobilização e a discussão, podendo servir também como fonte de informação para a produção de notícias (SKOGERBØ; KRUMSVIK, 2015; ENLI; SKOGERBØ, 2013).

Desta forma, as pesquisas envolvendo comunicação política e Twitter concentram-se em três principais categorias: o uso da ferramenta por candidatos e partidos, seu uso por públicos politicamente ativos e seu uso e reações em eventos mediados (JUNGHERR, 2016). $\mathrm{O}$ uso por parte de candidatos e partidos refere-se às formas de comunicação dos candidatos durante períodos eleitorais (ENLI; SKOGERBØ, 2013; VERGERR; HERMANS, 2013; CERVI; MASSUCHIN, 2013), enquanto o uso por públicos politicamente ativos refere-se a usuários que publicaram mensagens com hashtags ou palavras-chave politicamente relevantes e àqueles que seguiram as contas de candidatos ou partidos (JUNGHERR; SCHOEN; JÜRGENS, 2016; BODE et al., 2015). O terceiro grupo procura identificar mensagens postadas durante debates televisionados e entrevistas — ou seja, de que forma o público procura intervir durante estes eventos (ELMER, 2012; RECUERO, 2016).

$\mathrm{Na}$ campanha eleitoral para o parlamento europeu em 2009, por exemplo, o uso do Twitter por parte dos candidatos foi baixo. Ainda, os candidatos que mais utilizaram a ferramenta eram oriundos de partidos progressistas, enquanto os conservadores praticamente não usaram a ferramenta (VERGEER; HERMANS; SAMS, 2013). Nas eleições para o parlamento holandês em 2010, por sua vez, os candidatos que foram derrotados nas eleições anteriores utilizaram o Twitter de maneira mais intensa, o que pode indicar que estavam buscando novas maneiras de atingir o eleitorado (VERGERR; HERMANS, 2013).

Dentre as pesquisas que analisam o uso do Twitter por candidatos e partidos, destacamse alguns resultados: partidos da oposição tendem a utilizar o Twitter com maior frequência (VERGEER; HERMANS; SAMS, 2013); os candidatos utilizam a ferramenta para a divulgação de atividades de suas campanhas e não para dialogar com eleitores ou adversários (GRAHAM et al., 2013); e candidatos mais jovens utilizam mais frequentemente a ferramenta (JACKSON; LILLEKER, 2011; LASSEN; BROWN, 2011). 
Embora a utilização do Twitter como estratégia de comunicação eleitoral já exista desde 2008, a utilização das redes sociais digitais como estratégia de comunicação eleitoral foi autorizada no Brasil somente em 2009, através da Lei 12.034. Portanto, foi a partir das eleições de 2010 que ocorreu a incorporação das redes sociais digitais nas campanhas eleitorais brasileiras (AGGIO, 2016), e já nestas eleições o Twitter assumiu um papel de destaque nas campanhas dos presidenciáveis Plinio de Arruda Sampaio, através de transmissões on-line e dos "tuitaços", e José Serra, mostrando que o uso destas ferramentas na comunicação política já não poderia mais ser ignorado pelos candidatos (MARQUES; SAMPAIO, 2011; (MARQUES; SILVA; MATOS, 2013).

Após ser permitida a utilização de redes sociais digitais nas campanhas eleitorais, muitos estudos surgiram no Brasil com a intenção de captar padrões e formas de utilização destas ferramentas pelos candidatos, bem como questões relacionadas a mobilização e sondagem de opinião (ROSSETTO; CARREIRO; ALMADA, 2013; RECUERO, 2016; PENTEADO; GOYA; FRANÇA, 2014; AGGIO, 2016; MARQUES; SILVA; MATOS, 2013; CERVI; MASSUCHIN, 2013).

Assim, os primeiros trabalhos brasileiros de comunicação política relacionados ao Twitter centravam-se nas eleições presidenciais de 2010 e procuravam verificar questões da interação entre candidato e eleitor (AGGIO, 2016; MARQUES; SILVA; MATOS, 2013). Dos tweets postados pelos três principais candidatos à presidência em 2010 (Marina Silva, José Serra e Dilma Rousseff), por exemplo, cerca de $48 \%$ promovia interação entre os candidatos e os eleitores (AGGIO, 2016). No entanto, tais pesquisas não se concentram somente em disputas presidenciais, existindo também pesquisas que procuram analisar a utilização do Twitter por candidatos durante as campanhas locais para disputas proporcionais, para o cargo de vereador (MARQUES; MONT'ALVERNE, 2014, 2016), para cargos majoritários, para eleições para governado estadual (CERVI; MASSUCHIN, 2013) e para a disputa de prefeituras (ITUASSU; et al., 2014; ASSUNÇÃO; SANTOS, 2013).

Outra possibilidade de análise do cenário eleitoral utilizando o Twitter é a de verificar, através do uso de hashtags ou de palavras-chave, o sentimento dos usuários em relação a determinado candidato. Nas eleições de 2014, foram verificados picos de utilização do Twitter durante os debates televisivos, o que mostra uma interação entre os meios de comunicação como entre a televisão e o conteúdo postado nas redes sociais (PENTEADO; GOYA; FRANÇA, 2014). Tal relação entre debates televisivos e a utilização do Twitter por parte dos candidatos e do público em geral tem mostrado que o número de mensagens postadas na rede 
HERMAN, F. Campanha eleitoral no Twitter: as estratégias dos candidatos na disputa para a prefeitura de Curitiba em 2016

social tende a aumentar nos dias em que os debates ocorrem (SHAMMA; KENNEDY; CHURCHILL, 2009; JUNGHERR, 2014).

Foi verificado que o pico máximo de mensagens postadas a respeito das eleições para cargos no parlamento europeu em 2009 ocorreu no dia de um debate via Twitter, organizado por um programa de rádio (VERGEER; HERMANS; SAMS, 2013). No mesmo sentido, durante as eleições suecas em 2010, pesquisadores perceberam que, além do dia das eleições, ocorreram grandes quantidades de mensagens tuitadas durante debates televisionados, e comícios (LARSSON; MOE, 2012).

Segundo Trilling (2015), o Twitter pode funcionar como um complemento ao debate televisionado, pois assuntos que foram pouco abordados no debate, ou até mesmo negligenciados, continuam sendo discutidos na ferramenta. Dessa forma, a atividade no Twitter apresenta um grande vínculo com eventos mediados (LARSSON; MOE, 2012).

Como já foi mencionado, existem pesquisas que procuram analisar a utilização do Twitter durante as campanhas para as prefeituras, como a análise das postagens do candidato Marcelo Freixo nas eleições de 2012, na cidade do Rio de Janeiro (ITUASSU; et al., 2014; ASSUNÇÃO; SANTOS, 2013). No entanto, em nenhum caso procura-se estabelecer um paralelo entre os motivos que poderiam causar a ocorrência de picos nas postagens dos candidatos. Assim, é neste sentido que a presente pesquisa procura apresentar sua contribuição científica.

Diante do exposto, pretende-se verificar se a ocorrência de eventos durante o período eleitoral, como a realização de debates e divulgação de pesquisas eleitorais, causou alterações na utilização do Twitter pelos candidatos à prefeitura de Curitiba nas eleições de 2016, sendo que existem razões, a serem apresentadas na seção seguinte, que melhor justificam a escolha deste caso específico. Portanto, procura-se identificar em que sentido as postagens dos candidatos no Twitter se alteram durante o período eleitoral e se tais eventos possuem alguma influência sobre essa alteração.

\section{CENÁRIO DAS ELEIÇÕES DE 2016 EM CURITIBA}

As eleições municipais de 2016 foram as primeiras após a minirreforma política de 2015, que promoveu mudanças na regra eleitoral. Entre as principais alterações aprovadas pela minirreforma, destaca-se a redução do calendário da campanha eleitoral, que passou a ser de 45 dias, visto que anteriormente as campanhas tinham duração de 90 dias. A partir dessas eleições, o período de exibição do Horário Gratuito de Propaganda Eleitoral (HGPE) passou a ser de 35 
dias, além de passar a ter somente dez minutos por candidato, com inserções de 70 minutos distribuídas ao longo do dia, sendo o percentual de $60 \%$ para prefeitos e de $40 \%$ para vereadores. Outra mudança foi o fim das doações de campanhas por empresas privadas (BRASIL, 2015).

Estas alterações, além de tornarem o período de campanha mais curto, reduziram também a disponibilidade de recursos financeiros. Este fato pode ter favorecido a utilização das redes sociais durante o período eleitoral, devido à sua capacidade de alcançar uma grande parte do público e à possibilidade de comunicação direta a baixo custo com o eleitorado (CONWAY; KENSKI; WANG, 2013).

As eleições para a Prefeitura Municipal de Curitiba em 2016 tiveram um total de nove candidatos concorrendo ao cargo de prefeito, sendo que sete deles fizeram uso do Twitter como parte da estratégia de comunicação política com seus eleitores. A escolha em se estudar a campanha eleitoral para a prefeitura de Curitiba deve-se ao fato de a cidade possuir a maior população, colégio eleitoral e orçamento entre as capitais da região sul do Brasil (INSTITUTO BRASILEIRO DE GEOGRAFIA E ESTATÍSTICA, 2010; TRIBUNAL SUPERIOR ELEITORAL). Além desta importância populacional e socioeconômica, outro fator relevante é que a cidade ocupa o sexto lugar no ranking nacional de acesso domiciliar à internet, com cerca de $62 \%$ da população conectada (NÉRI; et al, 2012).

Os candidatos ao cargo de prefeito da cidade de Curitiba em 2016 foram: Ademar Pereira (PROS); Afonso Rangel (PRP); Gustavo Fruet (PDT); Maria Victória (PP); Ney Leprevost (PSD); Rafael Greca (PMN); Requião Filho (PMDB); Tadeu Veneri (PT); e Xênia Mello (PSOL).

A Tabela 1 apresenta os perfis dos candidatos ${ }^{5}$ no Twitter, bem como a data de criação da conta, o número de seguidores e o número de tweets postados até o início do período eleitoral:

\footnotetext{
${ }^{5} \mathrm{O}$ candidato Ademar Pereira (PROS) não utilizou o Twitter como estratégia de campanha e o candidato Afonso Rangel (PRP) teve sua candidatura impugnada.
} 
HERMAN, F. Campanha eleitoral no Twitter: as estratégias dos candidatos na disputa para a prefeitura de Curitiba em 2016

TABELA 1 - PERFIL DOS CANDIDATOS NO TWITTER

\begin{tabular}{c|c|c|c|c|c}
\hline CANDIDATO & PARTIDO & $\begin{array}{c}\text { PERFIL NO } \\
\text { TWITTER }\end{array}$ & $\begin{array}{c}\text { CRIAÇÃO DA } \\
\text { CONTA }\end{array}$ & SEGUIDORES & TWEETS \\
\hline Gustavo Fruet & PDT & @ gustavofruet & 20 de abril de 2009 & 73971 & 16927 \\
\hline Maria Victória & PP & @ mvictoriabb & 7 de julho de 2014 & 8529 & 895 \\
\hline Ney Leprevost & PSD & @ neyleprevost & 2 de julho de 2009 & 4046 & 24594 \\
\hline Rafael Greca & PMN & @ RafaelGreca33 & 14 de janeiro de 2010 & 11533 & 19985 \\
\hline Requião Filho & PMDB & @ RequiaoFilho & 12 julho de 2011 & 5050 & 12177 \\
\hline Tadeu Veneri & PT & @ tadeuveneri & 28 de abril de 2010 & 6923 & 10202 \\
\hline Xênia Mello & PSOL & @ xeniamello & 29 de março de 2010 & 159 & 112 \\
\hline
\end{tabular}

FONTE: Twitter.

Além das alterações nas regras de campanha, outro ponto que deve ser destacado é que o pleito de 2016 foi marcado pelo embate entre candidatos já tradicionais na política paranaense, tais como Rafael Greca (ex-prefeito da cidade, ex-deputado estadual e ex-deputado federal pelo estado do Paraná) e Gustavo Fruet (prefeito em exercício e ex-deputado federal), e uma nova geração de políticos — que, no entanto, representavam famílias já tradicionais na política paranaense, tais como Requião Filho, filho do Senador Roberto Requião (que já foi exprefeito de Curitiba e ex-governador do Paraná) e Maria Victória, da família Barros, filha do ministro da saúde Ricardo Barros e da vice-governadora Cida Borghetti.

\section{METODOLOGIA}

O corpus empírico da pesquisa é constituído por 1807 tweets $^{6}$, postados no Twitter pelos sete candidatos que utilizaram a ferramenta como estratégia de campanha durante o período eleitoral, compreendido entre os dias 16 de agosto e 1 de outubro de 2016,. Destaca-se que somente os tweets emitidos diretamente pelos candidatos foram coletados — ou seja, retweets e menções de outros usuários não foram considerados na coleta. Tal escolha deve-se ao fato de que se pretende analisar apenas os tweets emitidos pelo próprio candidato e não suas interações com outros usuários.

A coleta dos tweets foi efetuada semanalmente através da ferramenta de monitoramento de redes Twitonomy, que captura informações através do API $^{7}$ do Twitter, o que permite, além de efetuar a coleta e a captura de informações dos tweets, analisar um determinado perfil. Entre as principais funcionalidades da ferramenta Twitonomy, destaca-se

\footnotetext{
${ }^{6}$ Durante o período da pesquisa os candidatos postaram um total de 3145 tweets. Porém, para esta pesquisa foram classificados somente os tweets emitidos pelos candidatos, ou seja, retweets e respostas foram excluídos do corpus, o que resultou no total de 1807 mensagens.

${ }^{7}$ Application Programming Interface.
} 
que ela apresenta estatísticas sobre a conta pesquisada, tais como a quantidade de tweets postados durante o período de pesquisa e um agrupamento por palavras-chaves (hashtags) utilizadas pelo usuário. Cabe ressaltar que tal ferramenta já é utilizada em pesquisas que abordam o uso do Twitter em eleições, como a de Holtz-Bacha et al. (2017).

Desta forma, para verificar se acontecimentos ocorridos durante a campanha, tais como debates e pesquisas eleitorais, alteram a frequência de postagens dos candidatos, foram escolhidos cinco momentos (M) durante o período, buscando-se compreender quais possíveis fatores motivaram estas alterações no uso da ferramenta. Estes momentos (M) são: M1 — 22 de agosto de 2016 - Primeiro debate entre os candidatos; M2 - 23 de agosto de 2016 Divulgação da primeira pesquisa eleitoral do IBOPE; M3 - 19 de setembro de 2016 Divulgação da segundo pesquisa eleitoral do IBOPE; e M4 - 25 de setembro de 2016 Segundo debate entre os candidatos; M5 - 29 de setembro de 2016 - Terceiro debate entre os candidatos.

Foram escolhidas estas datas devido ao fato de debates televisionados possuírem a capacidade de concentrar uma grande audiência dos eleitores, produzindo notícias e discussões posteriores e aumentando fortemente o volume de mensagens políticas em reação a tal evento de mídia programado e anunciado (BENOIT, 2015a; JUNGHERR, 2014).

A escolha das datas nas quais foram divulgados resultados de pesquisas eleitorais pelo instituto IBOPE justifica-se pelo fato de que pesquisas eleitorais podem influenciar a decisão tanto dos candidatos quanto dos eleitores (COX, 1997). Outro ponto de destaque é que candidatos que estão na liderança das pesquisas tendem a ser mais atacados pelos seus concorrentes (BENOIT, 2015a).

Diante do exposto, os tweets postados foram objeto de análise quantitativa, em que foi verificada a distribuição temporal das mensagens durante o período em questão. Com o objetivo de entender quais os usos que os candidatos fazem da ferramenta e se debates e resultados de pesquisas eleitorais afetaram o conteúdo das postagens dos candidatos, foi realizada uma análise qualitativa deste conteúdo.

Em relação à parte qualitativa da pesquisa, foi efetuada uma análise de conteúdo das postagens efetuadas pelos candidatos, classificando-se o conteúdo dos tweets em categorias. Destaca-se que diversos trabalhos nacionais e internacionais fazem uso de categorização ao analisar o uso de redes sociais digitais por candidatos, utilizando diversas formas para estabelecer a categorização do conteúdo postado (MARQUES; SILVA; MATOS, 2013; CERVI; MASSUCHIN, 2013; ITUASSU; et al., 2014; ASSUNÇÃO; SANTOS, 2013; AGGIO, 2016; CARLOMAGNO; BRAGA, 2016). 
HERMAN, F. Campanha eleitoral no Twitter: as estratégias dos candidatos na disputa para a prefeitura de Curitiba em 2016

Para a presente pesquisa, o conteúdo das postagens foi classificado conforme uma metodologia adaptada de Parmelee e Bichard (2012, p. 178). Os autores analisaram doze disputas eleitorais nos Estados Unidos em 2010, para os cargos de senador e governador, em dez estados diferentes, classificando os tweets postados em sete diferentes categorias: Campaign Trail; Personal; Candidate Ideology; Opponent-Focused; Call to Action; Endorsements; e Unsure/Others.

Diante da classificação utilizada pelos autores, foi efetuada uma adaptação das categorias para o cenário brasileiro, e as postagens dos candidatos à prefeitura de Curitiba em 2016 foram classificadas da seguinte maneira:

Agenda e eventos: temas relacionados à divulgação de agenda e eventos do candidato, como visita a bairros, comícios e entrevistas.

Exemplo: Não perca, daqui a pouquinho, às $22 \mathrm{~h} 45$, participo do debate com os candidatos à prefeitura de Curitiba na RICTV Record Curitiba! :) (@mVictóriabb em 25/09/2016 às 18:31).

Imagem pessoal: mensagens de apoio recebidas pelo candidato e divulgação de realizações pregressas vinculadas à sua imagem.

Exemplo: Somos a gestão que menos gastou em propaganda e que mais investiu no meio ambiente \#EquipeGF (@ gustavofruet em 29/09/2016 às 19:32).

Posicionamento: posicionamento do candidato referente a ideologia, como posição política, ou a manifestações da população, como protestos.

Exemplo: Ney é o único candidato a prefeito que participou das manifestações contra a corrupção $e \quad a \ldots$ https://www.instagram.com/p/BJyL_KKhEPp/ (@neyleprevost em 31/08/2016 às 12:05).

Campanha negativa: ataques a adversários.

Exemplo: A única forma de enfrentar o problema da mobilidade é ter a coragem de enfrentar a máfia do transporte, coisa que o Fruet não fez \#XêniaNaBand (@xeniamello em 22/08/2016 às 19:30).

Mobilização e engajamento: convite relacionado a participação e mobilização, seja através de doações ou sugerindo-se a mudança da foto de perfil da rede social em apoio ao candidato.

Exemplo: Coloque a marca da campanha no seu avatar e participe da grande corrente de amor por Curitiba. \#VoltaGreca33 
http://twibbon.com/support/volta-greca-33... (@RafaelGreca33 em 01/09/2016 às 08:15).

Promessas e projetos: divulgação de propostas e promessas.

Exemplo: \#debatenaRPC \#emprego Nós precisamos investir em serviços para aumentar a geração de empregos. Um caminho é diminuir a burocracia. (@tadeuveneri em 29/09/2016 às 19:02).

Outros: categorias não englobadas anteriormente.

Exemplo: \#GinaIndelicada IIII) (@RequiaoFilho em 01/10/2016 às 09:36).

Após ser efetuada a classificação das postagens nas sete categorias, o período em que foram coletados os tweets, compreendido entre os dias 16 de agosto e 1 de outubro, foi subdividido em sete semanas, da seguinte forma: primeira semana, de 16 de agosto a 22 de agosto; segunda semana, de 23 de agosto a 29 de agosto; terceira semana, de 30 de agosto a 05 de setembro; quarta semana, de 06 de setembro a 12 de setembro; quinta semana, de 13 de setembro a 19 de setembro; sexta semana, de 20 de setembro a 26 de setembro; e sétima semana, de 27 de setembro a 1 de outubro.

Esta divisão semanal tem como objetivo facilitar a visualização dos temas postados pelos candidatos durante todo o período eleitoral e, também, a tentativa de verificar se os momentos (M) exerceram alguma influência nos temas postados, pois o M1 encontra-se localizado dentro da primeira semana de campanha, o M2 na terceira semana, o M3 na quinta semana, o M4 na sexta semana e o M5 na sétima e última semana de campanha.

Cabe destacar que as mensagens postadas foram classificadas em somente uma categoria, ou seja, nenhuma mensagem foi duplicada (esteve presente em mais de uma categoria). Nos casos em que as postagens abordavam mais de um tema, elas foram classificadas de acordo com o assunto dominante. A análise se limitou ao texto publicado na mensagem, não sendo analisados possíveis links ou imagens postados junto com ela.

Conforme foi visto, os debates televisionados podem concentrar a audiência dos eleitores, proporcionar notícias e discussões posteriores (BENOIT, 2015a; JUNGHERR, 2014), enquanto o Twitter pode favorecer o aumento do volume de mensagens políticas e servir como um complemento ao debate televisionado (TRILLING, 2015; LARSSON; MOE, 2012). Ainda, as pesquisas podem influenciar a estratégia e a decisão tanto dos candidatos quanto dos eleitores (COX, 1997; BENOIT, 2015a). 
HERMAN, F. Campanha eleitoral no Twitter: as estratégias dos candidatos na disputa para a prefeitura de Curitiba em 2016

Diante do exposto, apresentam-se duas hipóteses de pesquisa: 1) nos dias em que forem realizados os debates os candidatos utilizaram o Twitter com maior intensidade; e 2) debates e divulgações de pesquisas provocaram alterações nos temas postados pelos candidatos.

\section{ANÁLISE E DISCUSSÃO DOS DADOS}

O período de campanha eleitoral em 2016, estabelecido pelo Tribunal Superior Eleitoral (TSE), no qual os candidatos podem utilizar redes sociais digitais para fazer campanha, corresponde ao período compreendido entre 16 de agosto de 2016 a 1 de outubro de 2016. Durante este período, os sete candidatos que utilizaram o Twitter como estratégia de campanha postaram um total de 1807 tweets.

TABELA 2 - POSTAGENS POR CANDIDATO DURANTE PERÍODO ELEITORAL

\begin{tabular}{c|c|c|c}
\hline CANDIDATO & PERFIL NO TWITTER & TWEETS & $\begin{array}{c}\text { \% DO } \\
\text { TOTAL }\end{array}$ \\
\hline Gustavo Fruet & @ gustavofruet & 636 & $35,2 \%$ \\
\hline Maria Victória & @ mvictoriabb & 25 & $1,38 \%$ \\
\hline Ney Leprevost & @ neyleprevost & 379 & $20,97 \%$ \\
\hline Rafael Greca & @ RafaelGreca33 & 238 & $13,17 \%$ \\
\hline Requião Filho & @ RequiaoFilho & 371 & $20,53 \%$ \\
\hline Tadeu Veneri & @ tadeuveneri & 122 & $6,75 \%$ \\
\hline Xênia Mello & @xeniamello & 36 & $1,99 \%$ \\
\hline & Total de postagens & 1807 & $100 \%$ \\
\hline
\end{tabular}

FONTE: Twitter.

Ao observar a tabela acima, verifica-se que o candidato que fez uso de forma mais intensa da ferramenta foi o candidato à reeleição Gustavo Fruet, com 636 tweets, seguido por Ney Leprevost, com 379 tweets, e por Requião Filho, com 371 tweets. Já dentre os que fizeram um menor uso da ferramenta, destacam-se as candidatas Maria Victória, com 25 tweets, e Xênia Mello, com 36 tweets. Mello utilizou o Twitter somente até o dia 26 de agosto de 2016, e 27 de suas postagens foram efetuadas nos dias 22 e 23 de agosto de 2016.

Um ponto de destaque desta análise inicial refere-se aos estudos que apontam que candidatos mais jovens tendem a utilizar mais as redes sociais (VERGERR; HERMANS, 2013; JACKSON; LILLEKER, 2011). Neste pleito, no entanto, tal evidência não foi constatada, pois as candidatas mais jovens na disputa, Maria Victória e Xênia Mello, foram as que menos fizeram uso do Twitter. Neste sentido, também se destaca que ambos os representantes de partidos de esquerda, Tadeu Veneri (PT) e Xênia Mello (PSOL), não figuraram entre os 
usuários mais frequentes de tais ferramentas, como já apresentado em outros estudos (GRUSSEL; NORD, 2012).

$\mathrm{Na}$ figura abaixo, a linha cinza apresenta a distribuição agregada das postagens ao longo da campanha, ou seja, a somatória das postagens efetuadas pelos candidatos agrupadas por dia.

\section{FIGURA 1 - POSTAGENS AGREGADAS DOS CANDIDATOS DURANTE O PERÍODO ELEITORAL}

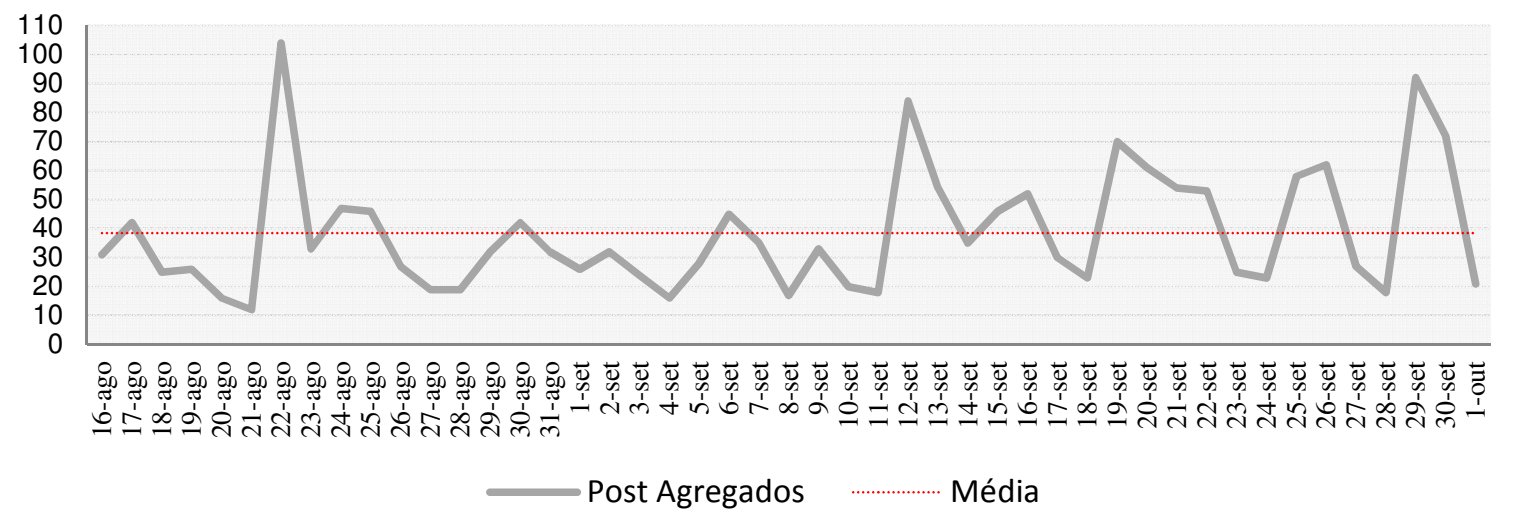

FONTE: Twitter.

Ao se observar a figura acima, verifica-se que algumas datas se destacam ao longo da campanha devido a uma grande quantidade de postagens dos candidatos, distanciando-se positivamente da média diária de postagens (38 posts por dia).

Conforme já foi dito, algumas datas apresentaram maior desvio em relação à média de postagens. Esta alteração também pode ser verificada pelo fato de em determinadas datas a atividade na ferramenta ter sido de maior intensidade pelo conjunto dos candidatos, e não por apenas um deles, desviando-se a média. 
HERMAN, F. Campanha eleitoral no Twitter: as estratégias dos candidatos na disputa para a prefeitura de Curitiba em 2016

FIGURA 2 - POSTAGENS POR CANDIDATO DURANTE PERÍODO ELEITORAL

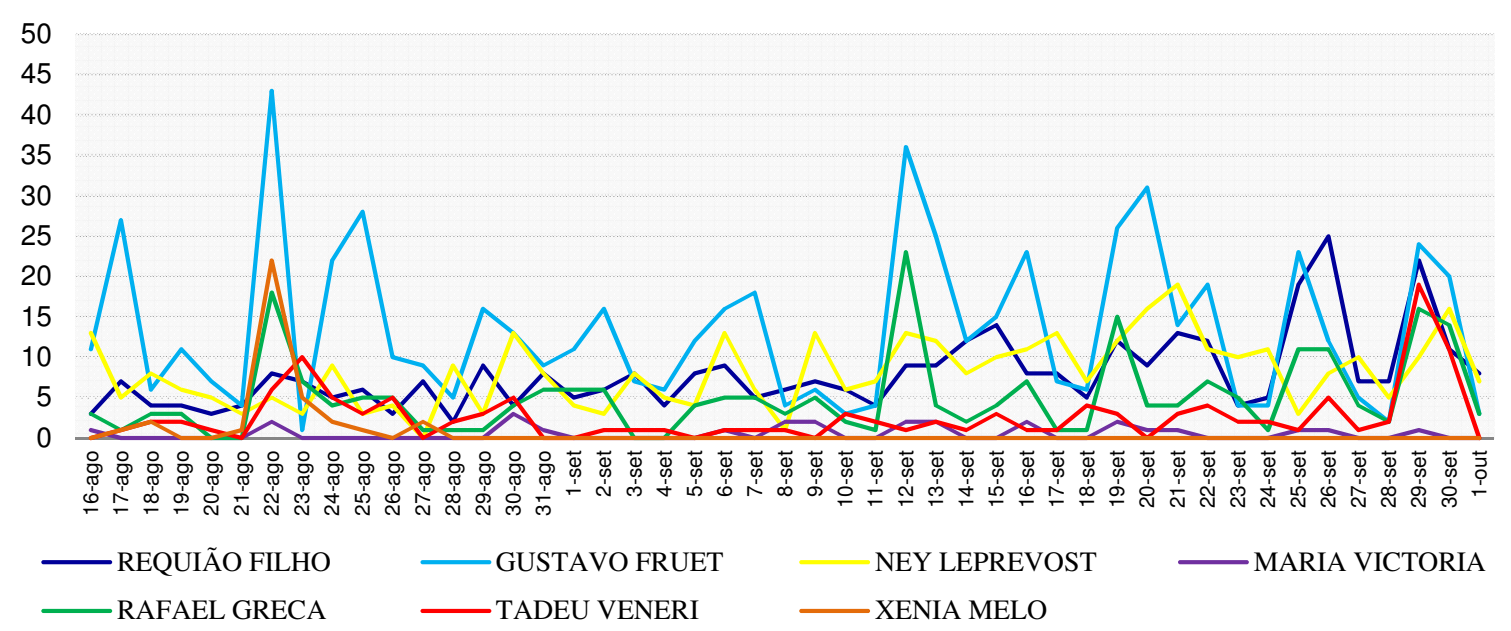

FONTE: Twitter.

Desta forma, destacamos alguns pontos $(\mathrm{P})$ que tiveram um maior desvio ${ }^{8}$ em relação à média: P1 — dia 22 de agosto de 2016, com 104 tweets; P2 — dia 12 de setembro de 2016, com 84 tweets; P3 — dia 19 de setembro de 2016, com 70 tweets; P4 — dia 20 de setembro de 2016, com 61 tweets; P5 - dia 26 de setembro de 2016, com 62 tweets; P6 - dia 29 de setembro de 2016, com 92 tweets; P7 - dia 30 de setembro de 2016, com 72 tweets.

Destes sete pontos (P), selecionados a partir de uma maior incidência de "tuitagem", três correspondem às mesmas datas escolhidas como momentos $(\mathrm{M})$ de campanha: $\mathrm{M} 1-22$ de agosto de 2016; M3 - 19 de setembro de 2016; e M5 - 29 de setembro de 2016. Portanto, verifica-se que em três dos momentos $(\mathrm{M})$ escolhidos ocorreram alterações quantitativas nas postagens dos candidatos.

Embora quatro dos pontos $(\mathrm{P})$ selecionados não correspondem a momentos $(\mathrm{M})$, podese dizer que três deles — o dia 20 de setembro de 2016 (P4), com 61 tweets; o dia 26 de setembro de 2016 (P5), com 62 tweets; e o dia 30 de setembro de 2016 (P7) — possuem ao menos uma relação de proximidade com eles, pois os três pontos correspondem ao dia seguinte a alguns dos momentos escolhidos.

A única data que não possui nenhuma relação de proximidade com nenhum momento (M) é o dia 12 de setembro de 2016. No entanto, nesta data ocorreu um debate entre os candidatos Gustavo Fruet e Rafael Greca, organizado pelo Jornal Gazeta do Povo. Embora o debate não tenha sido televisionado, ele foi transmitido ao vivo pelo Youtube e, nesta data, os

\footnotetext{
${ }^{8} \mathrm{O}$ desvio padrão representa uma medida de dispersão em torno da média. O desvio padrão das postagens diárias foi de 20,84, ou seja, nos pontos (P) selecionados a quantidade de tweets ficou acima da soma da média (39) + desvio padrão $(20,84)$, confirmado o alto desvio em relação à média.
} 
dois candidatos postaram um total de 59 tweets, o que corresponde a $70 \%$ do total de posts do dia.

O único momento (M) no qual não foi percebida uma alteração quantitativa que relacionasse o evento ao aumento das postagens foi o M2, dia 23 de agosto de 2016, data na qual foi divulgada a primeira pesquisa eleitoral, sendo que, neste dia, os candidatos postaram um total de 33 tweets.

Através desta comparação entre $\mathrm{P}$ e M, verifica-se que eventos correlatos à campanha podem exercer influência nas postagens dos candidatos, pois, dos sete pontos $(\mathrm{P})$ com maior incidência de tweets, seis se referem a datas próximas a debates ou à divulgação de pesquisas eleitorais. Diante de tal fato, pode-se especular que tais eventos (como debates) têm a capacidade de concentrar uma grande audiência dos eleitores e, também, de produzir notícias e discussões posteriores. Por isso, podem receber atenção especial dos candidatos nas campanhas, o que se reflete no aumento de publicações (BENOIT, 2015b).

Assim, o volume de mensagens políticas sobe fortemente em reação a um evento de mídia programado e anunciado, tal como um debate televisionado. Após este evento, o volume diário de mensagens tende a aumentar e se acumular até o dia das eleições (JUNGHERR, 2014).

Porém, apesar de os debates e de a divulgação de pesquisas eleitorais tenderem a aumentar as postagens dos candidatos, o ponto de análise mais construtivo não é apenas o de verificar este crescimento de forma quantitativa, mas de forma qualitativa, procurando-se entender, mais especificamente, como as postagens dos candidatos se alteram durante a campanha eleitoral e se elas são afetadas por tais eventos.

$\mathrm{Na}$ tabela abaixo são apresentadas as postagens dos candidatos de acordo com as categorias apresentadas na seção metodológica. As linhas da tabela indicam a frequência $(\mathrm{N})$ com que cada tema foi postado pelos candidatos, o percentual (\%) correspondente ao total de suas postagens e o resíduo padrão (R.P.), que permite identificar os valores quando a distribuição entre o valor esperado e o observado não é aleatória.

TABELA 3 - DISTRIBUIÇÃO DAS POSTAGENS DOS CANDIDATOS POR TEMAS

\begin{tabular}{|c|c|c|c|c|c|c|c|c|}
\hline \multicolumn{2}{|l|}{ Tema } & $\begin{array}{c}\text { Gustavo } \\
\text { Fruet }\end{array}$ & $\begin{array}{c}\text { Maria } \\
\text { Victória }\end{array}$ & $\begin{array}{c}\text { Ney } \\
\text { Leprevost }\end{array}$ & $\begin{array}{l}\text { Rafael } \\
\text { Greca }\end{array}$ & $\begin{array}{c}\text { Requião } \\
\text { Filho }\end{array}$ & $\begin{array}{c}\text { Tadeu } \\
\text { Veneri }\end{array}$ & $\begin{array}{l}\text { Xênia } \\
\text { Mello }\end{array}$ \\
\hline \multirow{3}{*}{ Agenda e eventos } & $\mathbf{N}$ & 127 & 11 & 118 & 59 & 102 & 58 & 8 \\
\hline & $\%$ & $20 \%$ & $44 \%$ & $31 \%$ & $25 \%$ & $27 \%$ & $48 \%$ & $22 \%$ \\
\hline & R.P. & $-3,298$ & 1,67 & 1,659 & $-0,579$ & 0,285 & 4,446 & $-0,523$ \\
\hline \multirow{2}{*}{ Imagem pessoal } & $\mathbf{N}$ & 222 & 0 & 30 & 21 & 18 & 5 & 2 \\
\hline & $\%$ & $35 \%$ & $0 \%$ & $8 \%$ & $9 \%$ & $5 \%$ & $4 \%$ & $6 \%$ \\
\hline
\end{tabular}


HERMAN, F. Campanha eleitoral no Twitter: as estratégias dos candidatos na disputa para a prefeitura de Curitiba em 2016

\begin{tabular}{|c|c|c|c|c|c|c|c|c|}
\hline & R.P. & 11,435 & $-2,03$ & $-4,111$ & $-2,913$ & $-5,521$ & $-3,371$ & $-1,616$ \\
\hline \multirow{3}{*}{ Posicionamento } & $\mathbf{N}$ & 3 & 1 & 10 & 0 & 9 & 5 & 0 \\
\hline & $\%$ & $0 \%$ & $4 \%$ & $3 \%$ & $0 \%$ & $2 \%$ & $4 \%$ & $0 \%$ \\
\hline & R.P. & $-2,184$ & 0,984 & 7,703 & $-1,92$ & 1,356 & 2,262 & $-0,747$ \\
\hline \multirow{3}{*}{ Campanha negativa } & $\mathbf{N}$ & 54 & 0 & 31 & 23 & 36 & 10 & 13 \\
\hline & $\%$ & $8 \%$ & $0 \%$ & $8 \%$ & $10 \%$ & $10 \%$ & $8 \%$ & $36 \%$ \\
\hline & R.P. & $-0,623$ & $-1,52$ & $-0,68$ & 0,214 & 0,293 & $-0,38$ & 5,303 \\
\hline \multirow{3}{*}{$\begin{array}{l}\text { Mobilização e } \\
\text { engajamento }\end{array}$} & $\mathbf{N}$ & 32 & 4 & 30 & 16 & 76 & 10 & 5 \\
\hline & $\%$ & $5 \%$ & $16 \%$ & $8 \%$ & $7 \%$ & $20 \%$ & $8 \%$ & $14 \%$ \\
\hline & R.P. & $-3,702$ & 1,038 & $-1,043$ & $-1,422$ & 6,792 & $-0,492$ & 0,837 \\
\hline \multirow{3}{*}{ Promessa e projetos } & $\mathbf{N}$ & 92 & 5 & 81 & 76 & 69 & 24 & 0 \\
\hline & $\%$ & $14 \%$ & $20 \%$ & $21 \%$ & $32 \%$ & $19 \%$ & $20 \%$ & $0 \%$ \\
\hline & R.P. & $-2,727$ & 0,091 & 0,964 & 4,481 & $-0,266$ & 0,118 & $-2,629$ \\
\hline \multirow{3}{*}{ Outros } & $\mathbf{N}$ & 106 & 4 & 79 & 43 & 61 & 10 & 8 \\
\hline & $\%$ & $17 \%$ & $16 \%$ & $21 \%$ & $18 \%$ & $16 \%$ & $8 \%$ & $22 \%$ \\
\hline & R.P. & $-0,331$ & $-0,146$ & 1,705 & 0,318 & $-0,357$ & $-2,4$ & 0,725 \\
\hline Total & & 636 & 25 & 379 & 238 & 371 & 122 & 36 \\
\hline
\end{tabular}

Qui-quadrado $=402,98$ (sig. 0,000); V de Cramer $=0,193$ (sig. 0,000).

FONTE: Twitter.

Para os dados acima apresentados foi efetuado o teste de qui-quadrado 9 (402,98), o qual foi significativo — ou seja, rejeita-se a hipótese nula de que não há relação entre as variáveis. Com isso, é possível, através dos resíduos padronizados, identificar a relação de força entre as variáveis. Assim, ao verificar-se a tabela, percebe-se que o candidato Gustavo Fruet foi quem mais efetuou postagens referentes ao tema Imagem pessoal, com 222 tweets, apresentando resíduo padrão ${ }^{10}$ de 11,435 , o que indica que o candidato teve forte relação com esta estratégia. Os posts relacionados a este tema destacavam as ações que Fruet fez durante seu mandato como prefeito.

Este achado encontra suporte na Teoria Funcional, de acordo com a qual uma mensagem política de campanha possui três funções: elogiar (declarações positivas sobre o candidato); atacar (criticar o oponente); e defender (refutação aos ataques) (BENOIT, 2015a). De acordo com esta teoria, candidatos que já estão no poder tendem a utilizar mais mensagens de aclamação, sendo este tipo de mensagem a estratégia dominante do mandatário, enquanto o ataque seria a estratégia do oposicionista. Embora a teoria seja utilizada para análise de debates,

\footnotetext{
${ }^{9} \mathrm{O}$ teste qui-quadrado é utilizado para verificar a relação entre variáveis qualitativas, sendo que se o teste é significativo rejeita-se a hipótese nula (ou seja, de que não existe relação entre as variáveis).

${ }^{10}$ Com o intervalo de confiança adotado de $95 \%$, qualquer resíduo maior ou menor que o ponto de corte de $+/-$ 1,96 é estatisticamente significativo, sendo, portanto, responsável pelas variações não aleatórias (CERVI, 2014).
} 
já existem trabalhos que a utilizam para análise de campanhas nas redes sociais digitais (BORAH, 2016).

O candidato Ney Leprevost destaca-se no tema Posicionamento (R.P. de 7,703), sendo que, durante a campanha eleitoral, o candidato apresentou-se ao eleitorado como o único a ter participado das manifestações contra a corrupção e a favor da operação Lava-Jato.

O candidato Requião Filho se destacou nos temas de Mobilização e engajamento, com 76 tweets (R.P. de 6,792). Durante a campanha, ele adotou diversas ferramentas de redes sociais digitais e procurou mobilizar seu eleitorado através de transmissões ao vivo.

A figura abaixo apresenta a análise de correspondência ${ }^{11}$ que visa medir o grau de associação entre as variáveis "candidatos" e os temas em que foram classificados seus tweets. Através da figura, é possível destacar a proximidade entre o candidato Fruet e o tema Imagem pessoal, entre o candidato Requião e os temas Mobilização e engajamento e Campanha negativa, e entre o candidato Rafael Greca e o tema Promessas e projetos — com resíduo padrão de 4,481, indicando que este foi o tema dominante nas postagens do candidato.

\section{FIGURA 3 - CORRESPONDÊNCIA ENTRE TEMAS E CANDIDATOS}

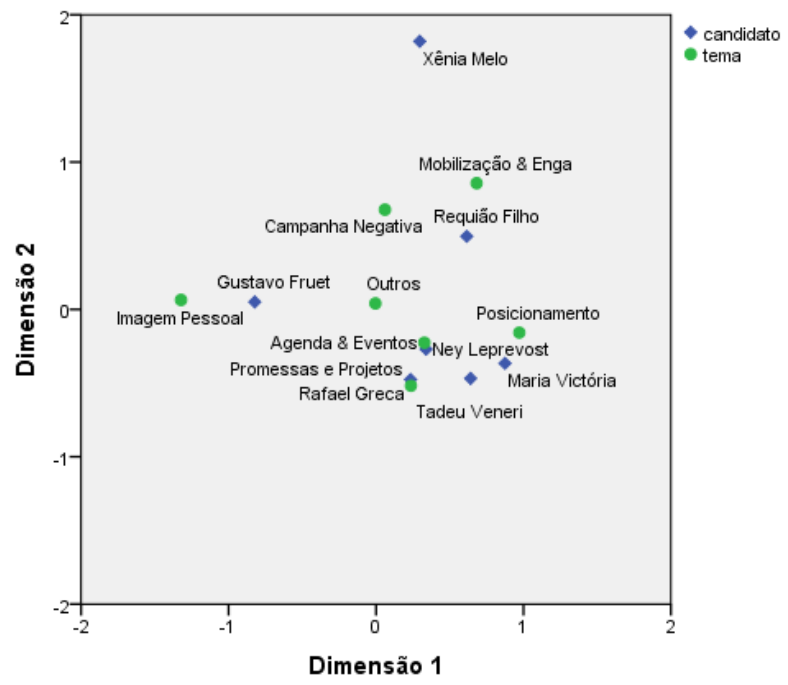

FONTE: O autor (2016).

A Figura 4 apresenta a evolução dos temas ao longo das sete semanas de campanha.

\footnotetext{
11 Para a análise de correspondência deve-se considerar os coeficientes de correlação e o de Inércia. O coeficiente de correlação mostra a correlação entre as variáveis e a dimensão, ou seja, quanto mais próximo de 1 maior o valor explicativo da dimensão. Os coeficientes para as duas dimensões (D) foram: D1=0,387; D2=0,179. O coeficiente de Inércia (I) significa a contribuição de cada dimensão para explicar a variância dos dados. A Inércia total foi de 0,223, refletindo a dispersão total dos pontos. Os coeficientes de Inércia (I) para as duas dimensões foram: $\mathrm{I} 1=0,150 ; \mathrm{I} 2=0,032$. Conforme dito anteriormente o teste qui-quadrado foi significativo 402,98 (sig. 0,000).
} 
HERMAN, F. Campanha eleitoral no Twitter: as estratégias dos candidatos na disputa para a prefeitura de Curitiba em 2016

\section{FIGURA 4 - EVOLUÇÃO TOTAL DOS TEMAS POR SEMANA}

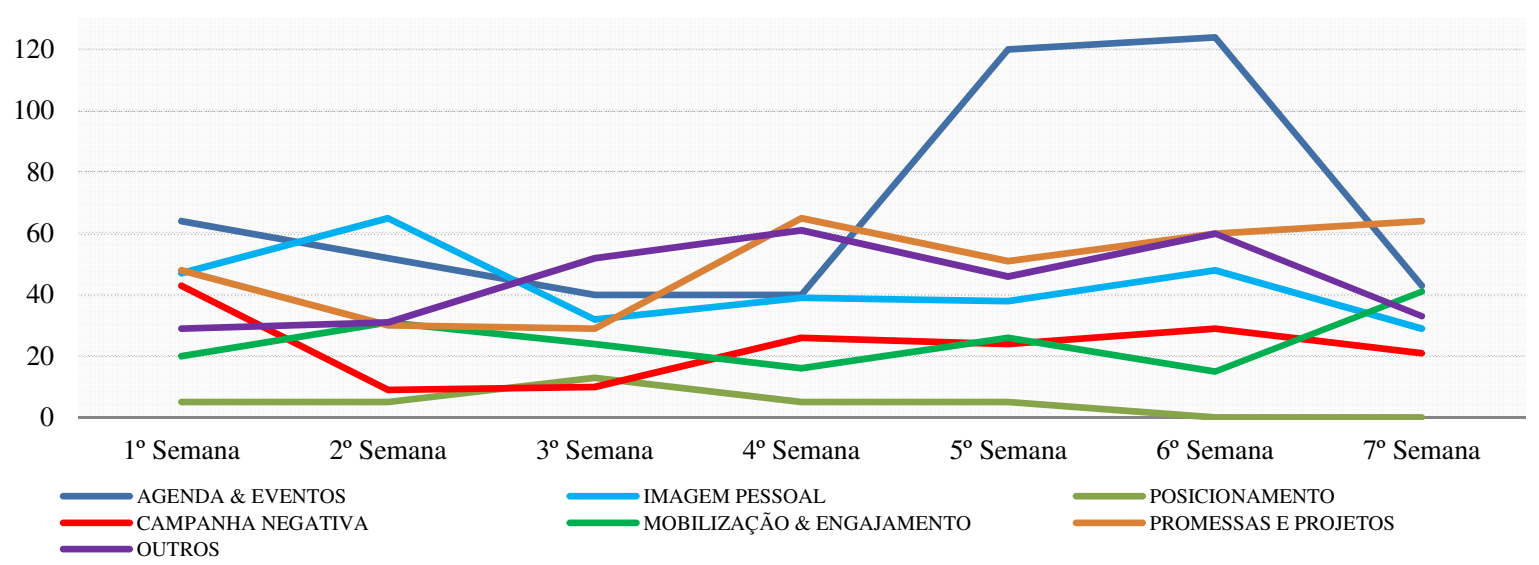

FONTE: Twitter.

Na primeira semana de campanha, os temas mais postados entre os candidatos são referentes a Agenda e eventos, Imagem pessoal e Promessas e projetos. Na primeira semana ocorre o contato inicial com o eleitorado, no qual o candidato procura se apresentar aos eleitores; portanto, é esperado que estes temas sejam dominantes em suas postagens. Após este contato inicial, o tema referente à Imagem pessoal apresenta uma redução gradativa na quantidade de mensagens, estabilizando-se em torno de uma média semanal de 35 tweets.

O tema Promessas e projetos apresenta crescimento no número de mensagens postadas a partir da terceira semana - ou seja, passado o momento inicial no qual o candidato busca apresentar-se ao eleitor, ele passa a direcionar sua campanha para a apresentação de suas propostas e projetos de forma mais frequente. Portanto, na primeira semana foram 48 tweets referentes ao tema, enquanto na última semana foram tuitadas 64 mensagens, percebendo-se uma taxa de crescimento de $33 \%$ nas mensagens relativas ao tema.

Ao analisar individualmente as postagens dos candidatos, verifica-se que a categoria Agenda e eventos atinge seu ápice nas semanas cinco e seis. Como este tema se refere a visitas a bairros e a entrevistas, percebe-se que, à medida que a campanha avança, é importante que o candidato continue a ampliar sua visibilidade entre os eleitores, divulgando sua agenda.

Ao verificar a evolução das postagens dos candidatos Fruet e Greca, observa-se que, na quarta semana, ambos os candidatos atingiram um aumento nas postagens categorizadas como Campanha negativa, estando Fruet com 12 e Greca com 7 tweets. Greca também atingiu seu ponto máximo referente a Promessas e projetos na quarta semana, com 20 posts. Isso pode ser explicado pelo fato de na quarta semana ter ocorrido, no Jornal Gazeta do Povo, um debate entre os dois candidatos, o que se reflete nas suas postagens. No que diz respeito às postagens 
dos dois candidatos referentes ao tema da Campanha negativa, Fruet postou 10 tweets e Greca postou 6 no dia do referido debate.

FIGURA 5 - EVOLUÇÃO SEMANAL DE TEMAS POR CANDIDATO

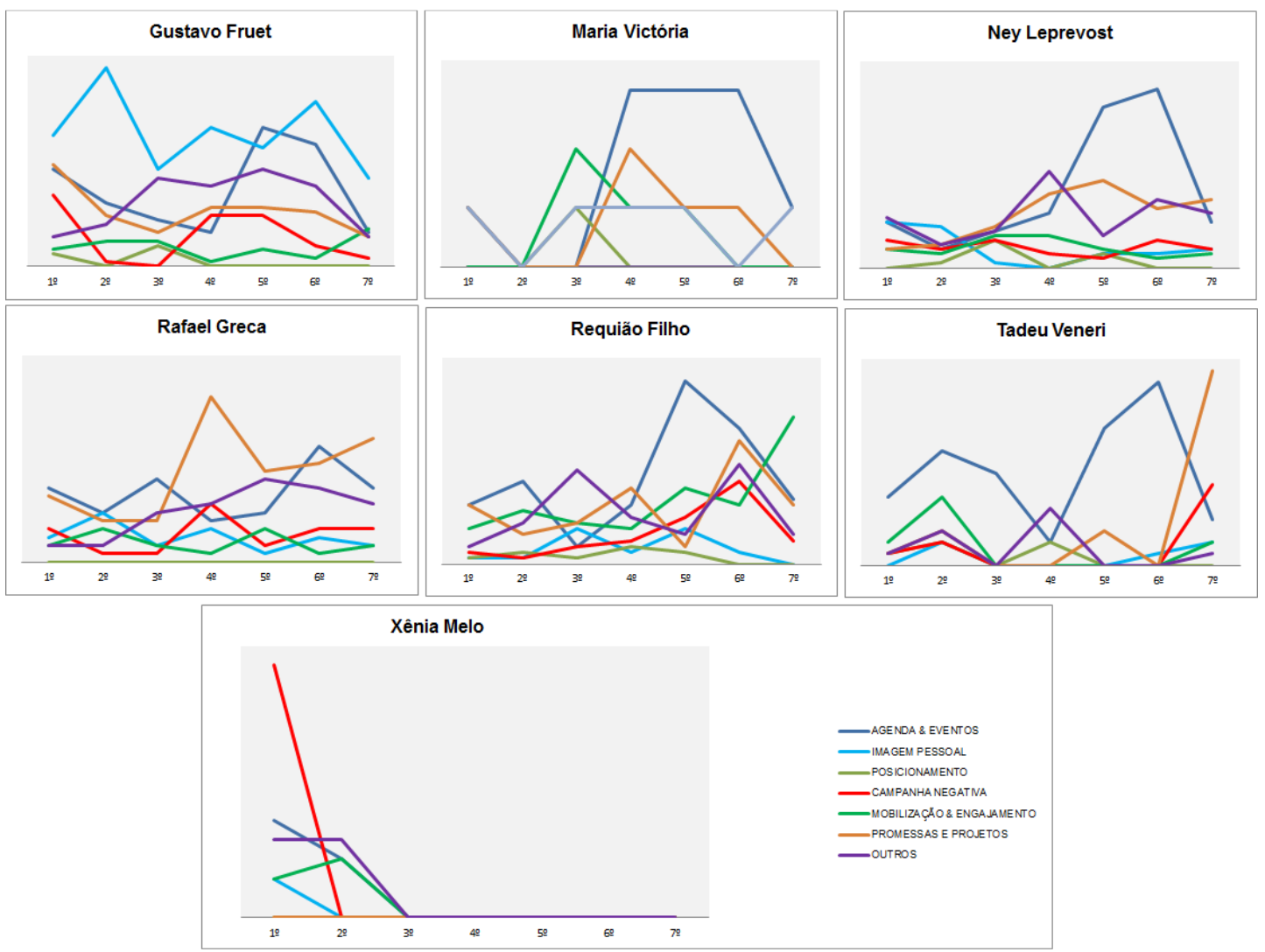

FONTE: Twitter.

No dia 19 de setembro (quinta semana), foi divulgada a segunda pesquisa eleitoral realizada pelo IBOPE, a qual apresentava os candidatos Rafael Greca e Gustavo Fruet em primeiro e segundo lugar, respectivamente, e os candidatos Requião Filho e Ney Leprevost logo atrás. Na semana seguinte, foi verificado que os candidatos Ney Leprevost e Requião Filho haviam tido um aumento nas postagens referentes ao tema da Campanha negativa, sendo que ambos atingiram o ápice de postagens relacionadas ao tema na sexta semana, estando Requião com 14 e Leprevost com 6 tweets.

Nas postagens feitas na última semana, observa-se que o tema Mobilização e engajamento teve um aumento entre todos os candidatos, com a exceção de Xênia Mello e Maria Victória. Desta forma, fica evidente que na reta final de campanha os candidatos procuram mobilizar seu eleitorado em busca do voto. 
HERMAN, F. Campanha eleitoral no Twitter: as estratégias dos candidatos na disputa para a prefeitura de Curitiba em 2016

O tema referente a Promessas e projetos também registrou aumento na quantidade de postagens na última semana, com 64 tweets. Entre os candidatos que mais postaram, destacamse Rafael Greca (15 tweets) e Tadeu Veneri (17 tweets).

Percebe-se, de maneira geral, que nas primeiras semanas as campanhas dos candidatos se preocupam mais com conteúdos referentes ao tema da Imagem pessoal, e que, à medida que o período eleitoral avança, os conteúdos mais postados passam a se referir a Promessas e Mobilização e engajamento.

\section{CONCLUSÃO}

O objetivo deste trabalho foi o de verificar de que forma as postagens no Twitter dos candidatos à prefeitura de Curitiba se alteram durante o período eleitoral, procurando identificar se eventos paralelos, tais como debates e pesquisas eleitorais, podem influenciar na utilização da ferramenta.

Diante dos dados apresentados, constata-se que tais eventos acabam por influenciar quantitativamente as postagens dos candidatos, pois, dos cinco momentos escolhidos, três apresentaram picos de postagens. Portanto, é possível afirmar que, nas datas em que foram realizados os debates televisionados, ocorreu um aumento no volume de postagens feitas pelos candidatos, sendo que os dias com o maior número de postagens foram o do primeiro e o do último debate, com 104 tweets em M1 (22 de agosto) e 92 tweets em M5 (29 de setembro).

Desta forma, a primeira hipótese da pesquisa foi confirmada, pois as datas em que ocorreram os debates foram os momentos em que se observou a maior quantidade de postagens dos candidatos. Assim, o Twitter funciona como uma continuidade do debate, pois, ao se analisar as mensagens postadas nos dias dos debates e nos dias seguintes a eles (dias 22 e 23 de agosto; dias 25 e 26 de setembro; e dias 29 e 30 de setembro) ${ }^{12}$, percebe-se que elas somaram um total de 421 tweets, representando um percentual de $23 \%$ do total de mensagens tuitadas. Assim, diante destes dados, é possível afirmar que o embate político se transporta dos debates para o universo on-line do Twitter.

Embora a data do dia 12 de setembro de 2016 não tenha sido escolhida previamente, através de sua análise é possível verificar uma relação direta das postagens dos candidatos com o debate do Jornal Gazeta do Povo. Nesta data foi registrado o maior número de postagens do candidato Rafael Greca, com 23 tweets, e o segundo dia com maior número de postagens do

\footnotetext{
${ }^{12}$ Utilizou-se esta combinação de datas pois todos os debates terminaram após a meia-noite e, assim, o conteúdo postado na continuidade do debate mudou para a data do dia seguinte.
} 
candidato Gustavo Fruet, com 36 tweets. Para ambos os candidatos, esta data foi a que apresentou a maior quantidade de posts relacionados ao tema da Campanha negativa. Greca, no dia 12 de setembro de 2016, efetuou 6 tweets com esta temática, todos destinados a Gustavo Fruet e a sua gestão como atual prefeito. Já Fruet postou 10 tweets, todos também direcionados a Greca e a seus apoiadores.

Em relação à segunda hipótese da pesquisa, de acordo com a qual se esperava que debates e divulgações de pesquisas provocassem alterações nos temas postados pelos candidatos, não foi possível sua confirmação. Porém, pode-se constatar uma relação entre os eventos relacionados à divulgação de resultados de pesquisas eleitorais e ao tema da Campanha negativa. Como exemplo, observa-se que os candidatos Ney Leprevost e Requião Filho ampliaram suas postagens de Campanha negativa logo na semana seguinte à divulgação das pesquisas. Desta forma, de acordo com a Teoria Funcional, pode-se observar que candidatos que não estão na liderança das pesquisas tendem a efetuar mais ataques. Neste sentido, verificase que o candidato Rafael Greca, que liderou todas as pesquisas divulgadas, foi um dos que menos postou mensagens referentes ao tema.

Por figurar na liderança das pesquisas eleitorais, percebe-se que o candidato Rafael Greca adotou uma estratégia de mandatário, com poucas postagens de Campanha negativa. Porém, quando houve um debate contra o prefeito em exercício na época (segundo colocado nas pesquisas), Greca passou a adotar a estratégia de ataque, concentrando $26 \%$ de seus tweets de Campanha negativa em uma única data (no dia do debate contra Fruet, 12 de setembro). Já os candidatos Gustavo Fruet, Ney Leprevost e Requião Filho adotaram a estratégia de ataque, pois não figuravam entre os líderes das pesquisas eleitorais, conforme aponta a Teoria Funcional.

Por fim, cabe destacar que o Twitter representa apenas uma das diversas possibilidades de os candidatos efetuarem campanhas eleitorais. Assim, como sugestão de pesquisa futura, seria importante efetuar uma análise que comparasse mais de uma plataforma de rede social digital, como o Facebook, e, com isso, constatasse se tais plataformas possuem as mesmas finalidades ou se existem diferenças de uso diante das possibilidades de cada uma delas. 
HERMAN, F. Campanha eleitoral no Twitter: as estratégias dos candidatos na disputa para a prefeitura de Curitiba em 2016

\section{REFERÊNCIAS}

AGGIO, C. Campanhas online e twitter: a interação entre campanhas e eleitores nas eleições presidenciais brasileiras de 2010. Revista Famecos, Porto Alegre, v. 23, n. 1, p. 27, 10 nov. 2016.

ASSUNÇÃO, A. B. M.; SANTOS, J. G. Estratégias de campanha política online: análise do caso Marcelo Freixo nas eleições para a prefeitura do Rio de Janeiro em 2012. Trabalho apresentado no 5. Congresso da Associação Brasileira de Pesquisadores em Comunicação Política. Curitiba, 2013.

BENOIT, W. L. Political Election Debates. In: BARNHUST, K. G. et al. The International Encyclopedia of Political Communication. Malden, MA: Wiley Blackwell, 2015a. p. 351-361.

. Advertising, Political. In: BARNHUST, K. G. et al. The International Encyclopedia of Political Communication. Malden, MA: Wiley Blackwell, 2015b. p. 1-7.

BODE, L. et al. Candidate Networks, Citizen Clusters and Political Expression: Strategic Hashtag use in the 2010 midterms. The Annals of the American Academy of Political and Social Science, New York, v. 659, n. 1, p. 149-165, 2015.

BOR, S. E. Using Social Network Sites to Improve Communication Between Political Campaigns and Citizens in the 2012 Election. American Behavioral Scientist, Sedona, v. 58, n. 9, p. 1195-1213, 2013.

BORAH, P. Political Facebook Use: Campaign Strategies Used in 2008 and 2012 Presidential Elections. Journal of Information Technology \& Politics, v. 1681, May 2016.

BOYD, D. M.; ELLISON, N. B. Social Network Sites: Definition, History and Scholarship. Journal of Computer-Mediated Communication, v. 13, n. 1, p. 210-230, Oct. 2007.

BRASIL. Lei $\mathrm{n}^{\circ} 13.165$, de 29 de setembro de 2015. Altera as Leis $\mathrm{n}^{\circ} 9.504$, de 30 de setembro de 1997, n 9.096 , de 19 de setembro de 1995, e n ${ }^{\circ} 4.737$, de 15 de julho de 1965. Diário Oficial da União, Brasília, DF, n. 29, set. 2015. Edição extra.

BRASIL. Lei $\mathrm{n}^{\circ} 12.034$, de 29 de setembro de 2009. Altera as Leis $\mathrm{n}^{\circ} 9.096$, de 19 de setembro de 1995 - Lei dos Partidos Políticos, 9.504, de 30 de setembro de 1997, e no 4.737, de 15 de julho de 1965. Diário Oficial da União, Brasília, DF, n. 30, set. 2009.

CARLOMAGNO, M.; BRAGA, S. O que os pré-candidatos à prefeitura de Curitiba fizeram no Facebook em julho? Boletim informativo MEME: e-monitor eleitoral, n. 1. p. 1-8, ago. 2016. Disponível em: <https://goo.gl/ehEXxm> Acesso em 04/09/2016.

CERVI, E. U. Análise de Dados Categóricos em Ciência Política. PPGCP - UFPR, Curitiba, 2014. Ebook disponível em: <http://www.cpop.ufpr.br/publicacoes/analise-de-dadoscategoricos-em-ciencia-politica> Acesso em 21/05/2017.

CERVI, E. U.; MASSUCHIN, M. G. O uso do Twitter nas eleições de 2010: o microblog nas campanhas dos principais candidatos ao governo do Paraná. Contemporânea: comunicação e cultura, Salvador, v. 9, n. 2, p. 319-334, 2011. 
CONWAY, B. A.; KENSKI, K.; WANG, D. Twitter Use by Presidential Primary Candidates during the 2012 Campaign. American Behavioral Scientist, v. 57, n. 11, p. 1596-1610, 2013.

COX, G. W. Making Votes Count: Strategic Coordination in the World's Electoral System. United Kingdom: Cambridge University Press, 1997.

ELMER, G. Live Research: Twittering an Election Debate. New Media \& Society, Chicago, v. 15, n. 1, p. 18-30, 2012.

ENLI, G. S.; SKOGERB $\varnothing$, E. Personalized Campaigns in Party-Centred Politics. Information, Communication \& Society, v. 16, n. 5, p. 1-18, 2013.

GOMES, W.; et al. "Politics 2.0": a campanha online de Barack Obama em 2008. Revista de Sociologia e Política, Curitiba, v. 17, n. 34, p. 29-43, out. 2009.

GRAHAM, T. et al. Between Broadcasting Political Messages and Interacting With Voters: the Use of Twitter during the 2010 UK General Election Campaign. Information, Communication \& Society, v. 16, n. 5, p. 692-716, 2013.

GRUSSEL, M.; NORD, L. Three Attitudes to 140 Characters: the Use and Views of Twitter in Political Party Communications in Sweden. Public Communication Review, v. 2, n. 2, p.48-61, 2012.

HOLTZ-BACHA, C. et al. Twitter and Elections around the World: Campaigning in 140 Characters or Less. Londres: Routledge, 2017.

INSTITUTO BRASILEIRO DE GEOGRAFIA E ESTATÍSTICA (IBGE). Censo demográfico IBGE. 2010. Disponível em: <http://cidades.ibge.gov.br/xtras/home.php>. Acesso em 01/09/2016.

ITUASSU, A.; et al. Internet, eleições e democracia: o uso das redes sociais digitais por Marcelo Freixo na campanha de 2012 para a Prefeitura do Rio de Janeiro. Revista ComPolítica, Rio de Janeiro, v. 2, n. 4, ago./dez. 2014.

JACKSON, N.; LILLEKER, D. Microblogging, Constituency Service and Impression Management: UK MPs and the Use of Twitter. The Journal of Legislative Studies, v. 17, n. 1, p. 86-105, mar. 2011.

JUNGHERR, A. The Logic of Political Coverage on Twitter: Temporal Dynamics and Content. Journal of Communication, v. 64, n. 2, p. 239-259, 2014.

Four Functions of Digital Tools in Election Campaigns: the German Case. The International Journal of Press/Politics, v. 21, n. 3, p. 358-377, 2016.

JUNGHERR, A.; SCHOEN, H.; JÜRGENS, P. The Mediation of Politics through Twitter: an Analysis of Messages Posted during the Campaign for the German Federal Election 2013. Journal of Computer-Mediated Communication, v. 21, n. 1, p. 50-68, 2016. 
HERMAN, F. Campanha eleitoral no Twitter: as estratégias dos candidatos na disputa para a prefeitura de Curitiba em 2016

KENSKI, K.; CONWAY, B. A. Social media and elections. In: BENOIT, W. L. Praeger Handbook of Political Campaigning in the United States. California: Praeger, 2016.

LARSSON, A. O.; MOE, H. Studying Political Microblogging: Twitter Users in the 2010 Swedish Election Campaign. New Media \& Society, Chicago, v. 14, n. 5, p. 729-747, 2012.

LASSEN, D. S.; BROWN, A. R. Twitter: the Electoral Connection? Social Science Computer Review, v. 29, n. 4, p. 419-436, 2011.

MARQUES, F. P. J. A. Ciberpolitica. Salvador: EDUFBA, 2016.

MARQUES, F. P. J. A.; AQUINO, J. A.; MIOLA, E. Parlamentares, representação política e redes sociais digitais: perfis de uso do Twitter na Câmara dos Deputados. Opinião Pública, Campinas, v. 20, n. 2, p. 178-203, ago. 2014.

MARQUES, F. P. J. A.; MONT'ALVERNE, C. Mídias sociais e eleições: um estudo sobre as campanhas de reeleição dos vereadores de Fortaleza no Twitter. Fronteiras - Estudos Midiáticos, São Leopoldo, v. 16, n. 3, p. 228-242, 23 set. 2014.

How Important is Twitter to Local Elections in Brazil? A Case Study of Fortaleza City Council. Brazilian Political Science Review, São Paulo, v. 10, n. 3, p. 1-35, 2016.

MARQUES, F. P. J. A.; SAMPAIO, R. Internet e eleições 2010 no Brasil: rupturas e continuidades nos padrões mediáticos das campanhas políticas online. Revista Galáxia, São Paulo, v. n. 22, p. 208-221, dez. 2011.

MARQUES, F. P. J. A.; SILVA, F.W.O; MATOS, N. Estratégias de comunicação política online: uma análise do perfil de José Serra no Twitter. In: MARQUES, F. P. J. A.; SAMPAIO, R. C.; AGGIO, C. (Org.). Do clique à urna: internet, redes sociais e eleições no Brasil. Salvador: EDUFBA, 2013.

NÉRI, M.; et al. Mapa da exclusão digital. Rio de Janeiro: FGV/IBRE, 2012. Disponível em: $<$ http://www.cps.fgv.br/cps/bd/mid2012/MID_sumario.pdf> Acesso em 11/08/2016.

PARMELEE, J. H.; BICHARD, S. L. Politics and the Twitter Revolution: How Tweets Influence the Relationship between Political Leaders and the Public. Plymouth: Lexington, 2012.

PENTEADO, C. L.; GOYA, D. H.; FRANÇA, F. O. O debate político no Twitter nas eleições presidenciais de 2014 no Brasil. Em Debate, Belo Horizonte, v. 6, n. 6, p. 47-54, 2014.

RECUERO, R. O Twitter como esfera pública: como foram descritos os candidatos durante os debates presidenciais do $2^{\circ}$ turno de 2014? Revista Brasileira de Linguística Aplicada, Belo Horizonte, v. 16, n. 1, p. 157-180, mar. 2016.

ROSSETTO, G. P. N.; CARREIRO, R.; ALMADA, M. P. Twitter e comunicação política: limites e possibilidades. Revista ComPolítica, Rio de Janeiro, v. 3, n. 2, p. 189, dez. 2013. 
SCAMMELL, M. Election Campaign Communication. In: BARNHUST, K. G. et. al. The International Encyclopedia of Political Communication. Malden, MA: Wiley Blackwell, 2015. p. 351-361.

SHAMMA, D. A.; KENNEDY, L.; CHURCHILL, E. F. Tweet the Debates: Understanding Community Annotation of Uncollected Sources. In: BOLL, S. et al. (Ed.). WSM'09: Proceedings of the First ACM SIGMM International Workshop on Social Media. Nova York: ACM, 2009. p. 3-10.

SKOGERB $\emptyset$, E.; KRUMSVIK, A. H. Newspapers, Facebook and Twitter. Journalism Practice, v. 9, n. 3, p. 350-366, May 2015.

TRIBUNAL SUPERIOR ELEITORAL (TSE). Disponível em: <www.tse.jus.br/>. Acesso em 15/12/2016.

TRILLING, D. Two Different Debates? Investigating the Relationship Between a Political Debate on TV and Simultaneous Comments on Twitter. Social Science Computer Review, v. 33, n. 3, p. 259-276, 2015.

TWITONOMY. Disponível em: <http://www.twitonomy.com/>. Acesso em 16/08/2016.

VERGEER, M.; HERMANS, L. Campaigning on Twitter: Microblogging and Online Social Networking as Campaign Tools in the 2010 General Elections in the Netherlands. Journal of Computer-Mediated Communication, v. 18, n. 4, p. 399-419, 2013.

VERGEER, M.; HERMANS, L.; SAMS, S. Online Social Networks and Micro-blogging in Political Campaigning: the Exploration of a New Campaign Tool and a New Campaign Style. Party Politics, v. 19, n. 3, p. 477-501, May 2013.

WILLIAMS, C. B.; GULATI, G. J. Social networks in political campaigns: Facebook and the congressional elections of 2006 and 2008. New Media \& Society, Chicago, v. 15, n. 1, p. 5271, 1 fev. 2013. 